\title{
The Founder's Lecture 2009: advances in imaging of osteoporosis and osteoarthritis
}

\author{
Thomas Marc Link
}

Received: 1 June 2010 /Revised: 3 June 2010 / Accepted: 4 June 2010 /Published online: 20 June 2010

(C) The Author(s) 2010. This article is published with open access at Springerlink.com

\begin{abstract}
The objective of this review article is to provide an update on new developments in imaging of osteoporosis and osteoarthritis over the past three decades. A literature review is presented that summarizes the highlights in the development of bone mineral density measurements, bone structure imaging, and vertebral fracture assessment in osteoporosis as well as MR-based semiquantitative assessment of osteoarthritis and quantitative cartilage matrix imaging. This review focuses on techniques that have impacted patient management and therapeutic decision making or that potentially will affect patient care in the near future. Results of pertinent studies are presented and used for illustration. In summary, novel developments have significantly impacted imaging of osteoporosis and osteoarthritis over the past three decades.
\end{abstract}

Keywords Osteoporosis · Osteoarthritis ·

Quantitative imaging $\cdot \mathrm{MRI} \cdot \mathrm{CT}$

\section{Introduction}

Radiology still is mostly considered a medical science based on the morphological evaluation of anatomy and macroscopic pathology. Purely qualitative analysis, however, has limitations in quantifying disease processes, which is of considerable significance for patient management and scientific research studies. In particular, for analyses of the effects of novel techniques and their

T. M. Link $(\bowtie)$

Department of Radiology and Biomedical Imaging,

University of California at San Francisco,

400 Parnassus Ave, A-367,

San Francisco, CA 94131, USA

e-mail: tmlink@radiology.ucsf.edu impact on or use for therapeutic decision making, quantitative measurements are required. Bone mineral density measurements were among the first quantitative measurements in musculoskeletal radiology and have gained tremendous importance in diagnosing and treating osteoporosis as well as in monitoring therapy effects. In osteoarthritis also there have been increasing efforts to implement quantitative or semi-quantitative measurements, in particular using MR-based techniques. The following article reviews the developments and advances in osteoporosis and osteoarthritis imaging over the past three decades.

\section{Osteoporosis - from bone mineral density to structure imaging}

In the late 1970s and early 1980s, quantitative imaging was introduced to the study of bone mineral density (BMD) using quantitative computed tomography (QCT) $[1,2]$. At this time these concepts were novel and revolutionized the diagnosis and later the treatment of osteoporosis. QCT was standardized initially for the lumbar spine and later for the proximal femur [3, 4]. Initially single slice techniques were used that analyzed single, midvertebral sections of the L1-4 vertebral bodies with manual (Fig. 1) and later automatic software tools mostly to measure trabecular bone mineral density [2, 5, 6]. These techniques had limited precision, and volumetric techniques were therefore developed to improve applicability of QCT in longitudinal studies [3, 7-10].

Dual X-ray absorptiometry (DXA) [11, 12] was developed in parallel to QCT and, given that the technique did not require expensive CT equipment but used a dedicated scanner that was cheaper and had lower operating costs, DXA overtook QCT and is currently the standard for bone 


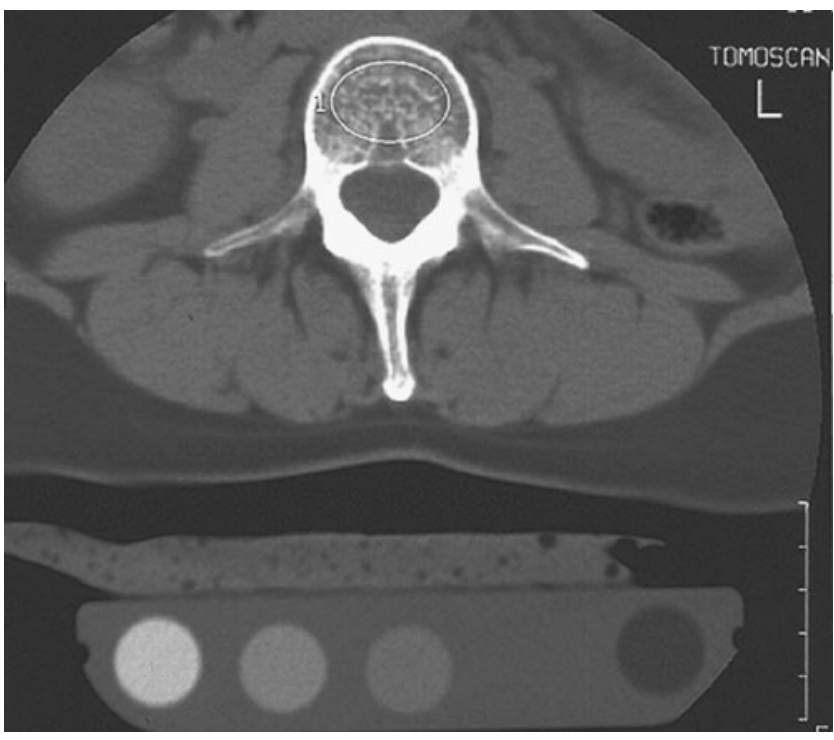

Fig. 1 Single-slice QCT of the lumbar spine with oval-shaped region of interest and five-element solid calibration phantom

densitometry measurements. In addition DXA has a high precision and DXA T-scores have been established to define osteoporosis and osteopenia according to WHO guidelines [13]. DXA has been used in multiple cross-sectional and longitudinal studies to differentiate individuals with and without fractures, assess fracture risk, and analyze therapy effects; thus the fund of knowledge for DXA is currently superior to QCT [14-18]. Though DXA only assesses areal BMD of the lumbar spine, proximal femur, and distal radius, which includes cortical and trabecular bone, and has limitations in patients with degenerative disease, it has been shown to be robust and a good technique to determine fracture risk and measure response to therapy.

\section{Osteoporosis—bone quality}

Because bone mass measured with DXA only accounts for $60-70 \%$ of the variation in bone strength [19], researchers have been motivated to better characterize in vivo bone strength in osteoporosis. In 1993 the NIH osteoporosis consensus panel defined osteoporosis as a disease characterized by fragility fractures due to low bone mass and deterioration of bone architecture [20]; in 2001 the bone quality concept was introduced, which also included bone architecture [21]. Given these new concepts and advances in radiology that allowed high resolution imaging of bone, research efforts increasingly focused on visualization of trabecular bone architecture and later also on cortical bone structure imaging.

Early studies used radiographs to assess trabecular bone structure and found significant correlations between biomechanically determined fracture load and structure measures
[22-24]. In vivo radiographs of the spine, the calcaneus, and the distal radius were used with good results to discriminate patients with and without osteoporotic fractures [25-29]. Today as structure analysis techniques are getting more sophisticated, there is renewed interest in using low cost radiographs to assess trabecular bone architecture [30]. However, a limitation of radiographs is that they represent an overall projection of the bone structure and do not demonstrate individual trabeculae; also the reproducible evaluation of bone structure is highly dependent on surrounding soft tissues, which significantly offsets clinical applicability.

Bone structure analysis was therefore applied to crosssectional imaging techniques employing high resolution CT [31-34], and promising results were found in predicting biomechanically determined bone strength using various texture measures including fractal dimension. With the development of multi-detector CT (MD-CT) scanners, higher spatial resolutions and better depiction of the trabecular bone structure in vivo became available [35-39] (Fig. 2). Initial clinical studies were performed to differentiate individuals with and without fractures and to monitor therapy [40, 41]. Ito et al. showed that vertebral microarchitecture can be visualized on MD-CT images, and microstructure parameters obtained by MD-CT, together with volumetric BMD, provided better diagnostic performance for differentiating subjects with and without osteoporotic vertebral fractures than DXA measurement [41]. Graeff et al. monitored effects of teriparatide on vertebral trabecular microstructure independent of BMD using high-resolution MD-CT in 65 postmenopausal women with established osteoporosis who participated in the EUROFORS study [40]. These investigators found statistically significant increases in microstructural variables after therapy; after 12 months apparent bone volume fraction (app. BV/TV) increased by $30.6 \pm 4.4 \%$ (SE), and apparent trabecular number (app. Tb.N.) increased by $19.0 \pm 3.2 \%$ compared with $6.4 \pm 0.7 \%$ for areal and $19.3 \pm$ $2.6 \%$ for volumetric BMD. Interestingly the structural changes were partially independent of BMD as shown by a significantly larger standardized increase and a standardized long-term precision that was at least as good as DXA.

One of the main limitations associated with extending the MD-CT technology to imaging trabecular bone structure in patients lies in the trade off between radiation exposure and spatial resolution. The higher the spatial resolution of images required, the greater the exposure to radiation, which greatly limits clinical applicability for imaging of the axial skeleton (spine and hip). While DXA has an effective dose of $0.01-0.05 \mathrm{mSv}$ in adults and QCT has an effective dose of $0.06-0.3 \mathrm{mSv}$, the referenced studies showed that protocols to examine vertebral microstructure using high resolution MD-CT subject patients to an effective dose of about $3 \mathrm{mSv}$. 

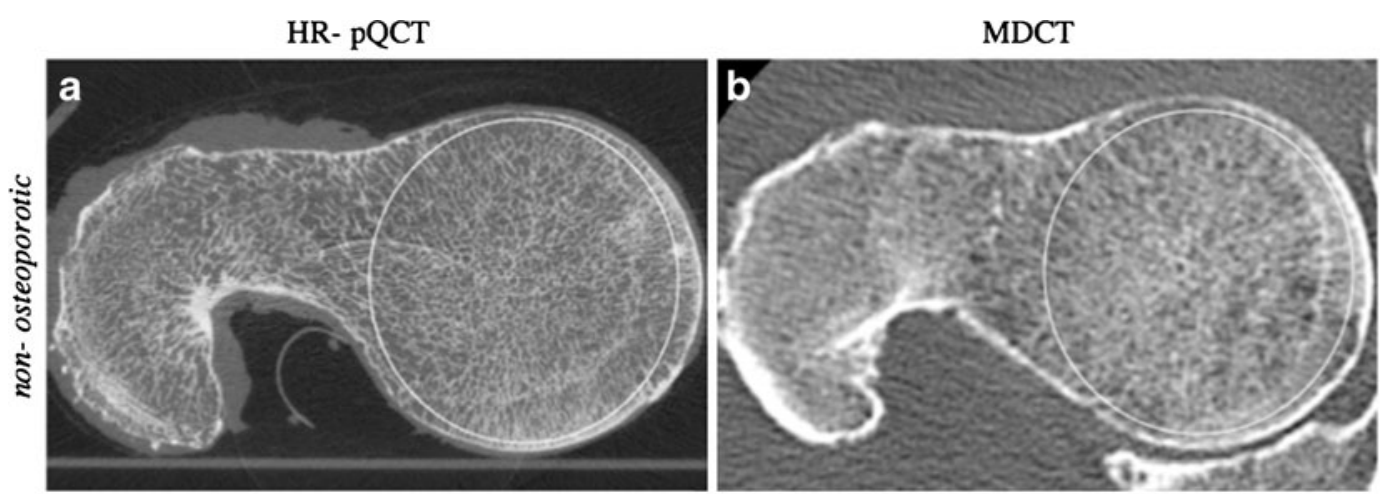

Texture Analysis
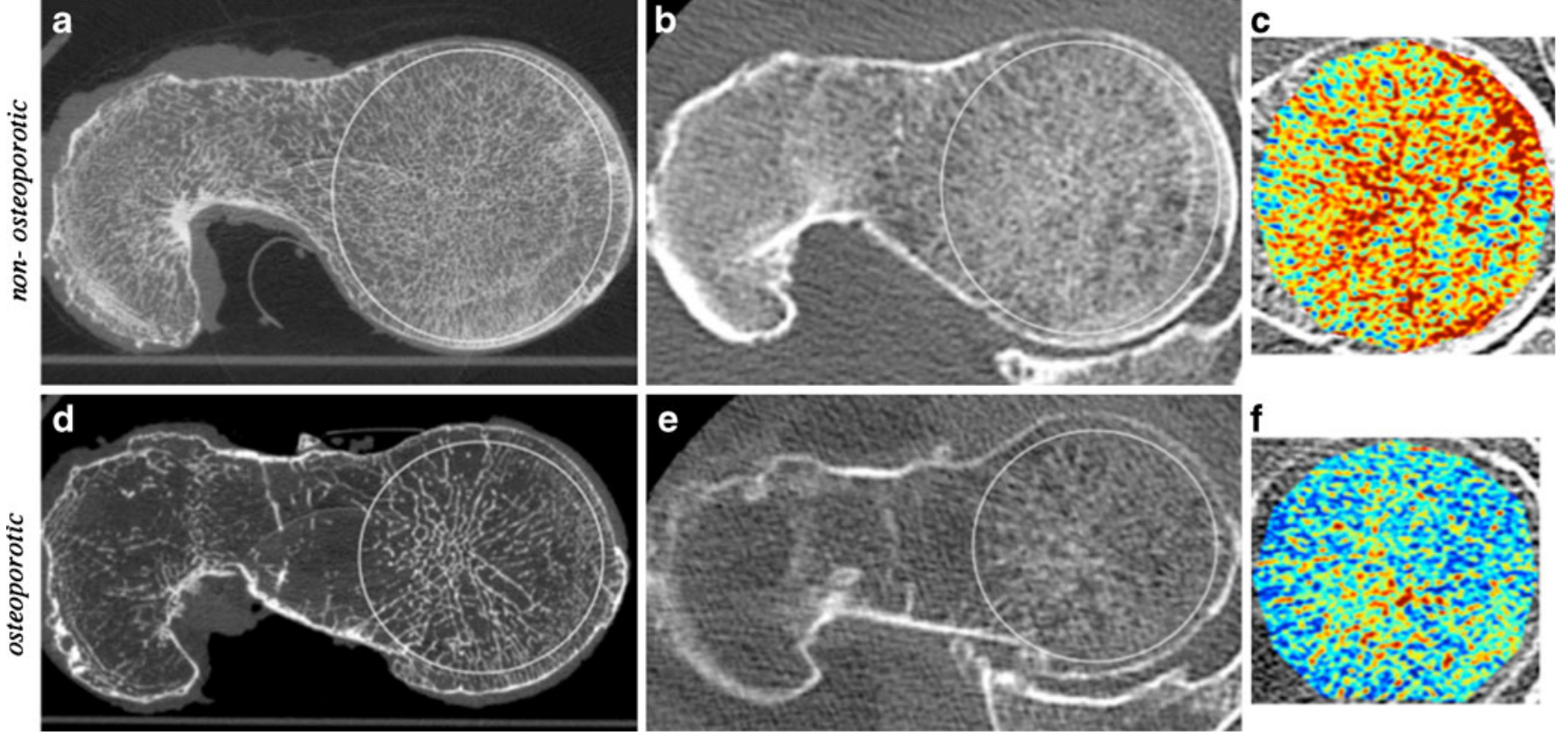

Fig. 2 High resolution MD-CT images of the proximal femur of two intact human cadavers $(\mathbf{b}, \mathbf{e})$ in comparison with specimen images obtained with high resolution peripheral QCT (hr-pQCT) (a, d) as a standard of reference. The body donor of a-c had no vertebral fractures and high values for femoral bone volume fraction and trabecular number. $\mathbf{d}-\mathbf{f}$ show images from a donor with structural parameters in the lowest range and multiple vertebral fractures. The

Recently a high resolution peripheral CT (hrp-QCT) scanner (XtremeCT, Scanco Medical, Brüttisellen, Switzerland) was developed for clinical imaging of trabecular and cortical bone architecture in the distal tibia and radius; it provides an isotropic spatial resolution and a voxel size of $82 \mu \mathrm{m}^{3}$. Compared to MD-CT, the effective radiation dose is substantially lower with a reported dose of $0.003 \mathrm{mSv}$ [42]. Using this system, the first published study found that postmenopausal women had lower density, trabecular number, and cortical thickness than premenopausal women $(P<0.001)$ at both radius and tibia [43]. Furthermore, it was found that, although spine and hip BMD were similar, fractured osteopenic women had lower trabecular density and more heterogeneous trabecular distribution at the radius compared with unfractured osteopenic women. The precision of these measurements was $2.5-4.4 \%$ for trabecular architecture parameters [43]. Representative images of the distal tibia obtained with this device are shown in Fig. 3. In addition to trabecular bone architecture assessment, hr-pQCT also allows analysis of cortical structural parameters [44-46]. In a recent study Burghardt et al. [44] analyzed cortical bone porosity in normal controls and diabetic patients with and without osteoporotic fractures. These investigators found a significant increase in cortical porosity in diabetic subjects, in particular in those with osteoporotic fractures (Fig. 4). The white line in the femoral head represents the region of interest for assessment of trabecular bone parameters. Images $\mathbf{c}$ and $\mathbf{f}$ are texture maps (density-color plots) of the detected trabecular network for texture analysis (range from red for pixels containing dense trabeculae to blue for pixels predominantly consisting of bone marrow). Images from reference [35]

results of this study suggest that cortical porosity may be a new powerful bone structure parameter for assessing bone strength.

In contrast to $\mathrm{CT}$, magnetic resonance imaging (MRI) does not require radiation but utilizes a strong magnetic field and a sequence of radiofrequency pulses to create cross-sectional images that may be obtained in each orientation in 3D space, which makes this technique attractive for scientific studies. With the advent of phased array coils and improved software and hardware including $3 \mathrm{~T}$ imaging, it has been possible to advance the frontiers of MRI concerning spatial resolution for imaging trabecular bone structure. A number of calibration and validation studies were performed in which MR-derived measures of structure were compared with measures derived from other modalities, such as histology, micro-CT, BMD, and with biomechanical parameters; in addition these measures were used to differentiate patients with and without osteoporotic fractures [47-52]. Most of the in vivo studies focused on imaging of the distal radius, the calcaneus, and the distal tibia as these sites have a large number of trabeculae and the distal radius is a typical site for osteoporotic fractures. Also these sites are easily accessible with localized surface coils, and subjects are able to comfortably tolerate immobilization for the period of time required for highresolution imaging. Figure 5 shows high resolution MR 
Fig. 3 High resolution peripheral QCT (hr-pQCT) images of the distal tibia (a) and distal radius (b) obtained in postmenopausal women. Both trabecular and cortical bone architecture are well depicted
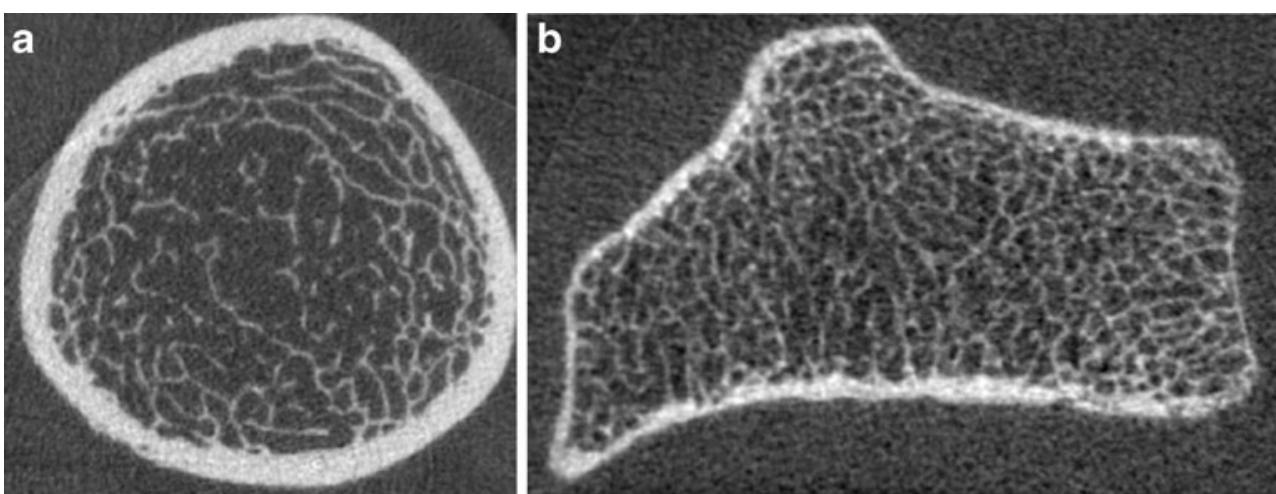

images depicting the trabecular bone architecture at the distal radius in a postmenopausal subject.

One of the early longitudinal studies using MRI showed that salmon calcitonin nasal spray had therapeutic benefit compared with placebo in maintaining trabecular microarchitecture at multiple skeletal sites and supported the use of MRI technology for assessment of trabecular microarchitecture in clinical research trials [53]. Another longitudinal study in hypogonadal men suggested that testosterone replacement improves trabecular architecture [54]. Interestingly it was also noted that structure parameters obtained from hr-pQCT were not directly comparable with those determined in high resolution MR studies [46]. Kazakia et al. found that MRI and hr-pQCT provided statistically different values of structure parameters $(P<0.0001)$, with trabecular bone fraction and trabecular thickness exhibiting the largest discrepancies $(\mathrm{MR} / \mathrm{hr}-\mathrm{pQCT}=3-4)$; differences in trabecular number values were also statistically significant, but the mean differences were on the order of the reproducibility measurements [46].

Through the use of MRI at higher field strength $(3.0 \mathrm{~T})$, visualization of trabecular bone architecture can be sub- stantially improved as demonstrated by Phan et al. [55]. These investigators showed in an in vitro study that MR imaging at 3.0 T provided a better measure of the trabecular bone structure than did MR imaging at $1.5 \mathrm{~T}$ using microCT measures as a standard of reference.

In addition to high resolution MRI, researchers also focused on quantitative MR techniques to assess water content of the cortical bone as a potential parameter to assess bone strength. This ultra-short echo time (UTE) imaging technique allows the detection of signal components with $\mathrm{T} 2$ relaxation times on the order of only a few hundred microseconds. These components are found in highly ordered tissues such as cortical bone and tendons and can not be detected with conventional imaging techniques, where TE is limited to $1-$ $2 \mathrm{~ms}$ [56]. Techawiboonwong et al. [57] recently reported UTE imaging with radial MR pulse sequences to characterize cortical bone water. These investigators validated the technique in adult sheep and human tibia specimens using an isotope exchange experiment and studied the right tibial midshaft in pre- and postmenopausal females and patients on hemodialysis. The quantitative analysis showed that bone water content was $135 \%$ higher in the patients on maintenance dialysis than in the premenopausal women and $43 \%$

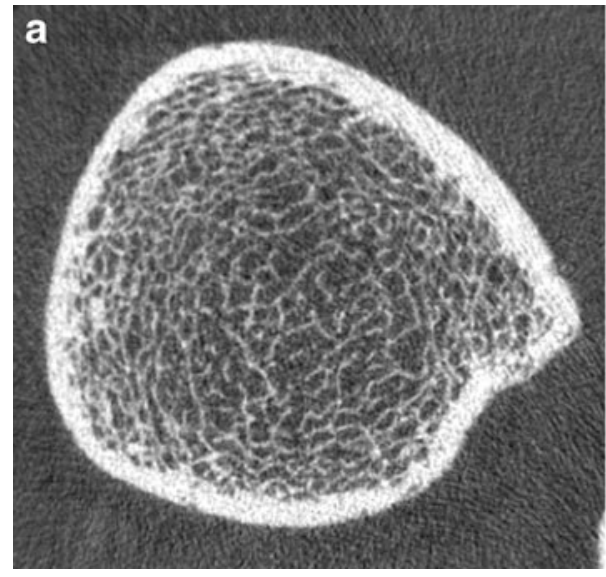

Fig. 4 High resolution peripheral QCT (hr-pQCT) images of the distal tibia in a postmenopausal woman without fractures (a) and a diabetic postmenopausal woman with osteoporotic fragility fractures

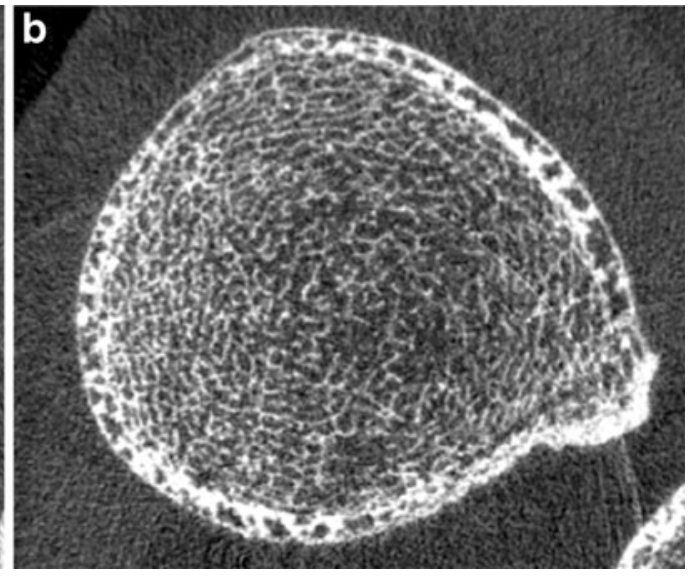

(b). Note the differences in cortical porosity, while the trabecular architecture appears well maintained in both images. Images from reference [44] 


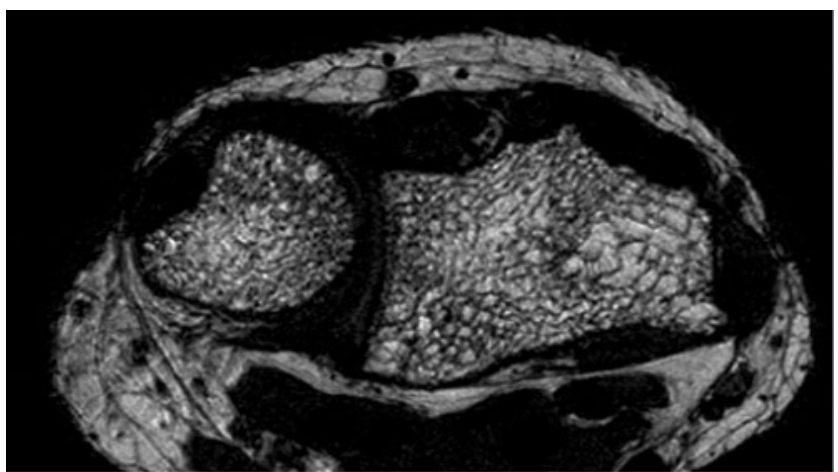

Fig. 5 MRI of the distal radius using a FIESTA (fast imaging employing steady state acquisition) sequence. The image depicts the heterogeneity of the trabecular bone architecture well in this postmenopausal woman

higher than in the postmenopausal women. Interestingly no significant differences were found in tibial volumetric BMD between patients on hemodialysis and pre- and postmenopausal normal controls.

\section{Osteoporosis-vertebral fracture assessment}

Previous studies have found a circa $10 \%$ prevalence of vertebral fractures in women in their $50 \mathrm{~s}$ and $25-45 \%$ in women in their $80 \mathrm{~s}[58,59]$. A large number of vertebral fractures do not come to clinical attention, although osteoporosis-related vertebral fractures have important health consequences for older women, including disability and increased mortality [60,61]. Also it should be noted that the presence of one vertebral fracture increases the risk of any subsequent vertebral fracture fivefold [62] and that $20 \%$ of the women with a diagnosed vertebral fracture will sustain a new fracture within the next 12 months [63]. Because further fractures can be prevented with appropriate medications, recognition and treatment of these high-risk patients is warranted.

In 2000, a cross-sectional study raised substantial concern that vertebral fractures may be underreported by radiologists [64]. In this survey Gehlbach et al. [64] reviewed PA and lateral chest radiographs that had been performed in 934 women aged 60 years and older who had been hospitalized. Moderate or severe vertebral fractures were identified in $132(14.1 \%)$ study subjects, but only $50 \%$ of the radiology reports identified a fracture as present, and only $17(1.8 \%)$ of the 934 patients had a discharge diagnosis of vertebral fracture. As a consequence, relatively few of these patients with vertebral fractures received appropriate osteoporosis-specific medications to prevent further fractures. Another study published by Kim et al. [65] analyzed PA and lateral chest radiographs of 100 randomly selected patients 60 years or older who presented to the emergency department of a tertiary care hospital. A clinically important vertebral fracture was defined as one that was at least moderate to severe (loss of height $\geq 25 \%$ ). The mean age of the population was 75 years, and $47 \%$ were women. According to a reference radiologist, the prevalence of moderate to severe vertebral fractures was $22 \%$ in this population. However, only $55 \%(12 / 22)$ of these vertebral fractures were mentioned in the official radiology reports.

The results of both of these studies showed that chest radiography has potential as a screening tool for revealing previously undiagnosed vertebral fractures (Fig. 6), but that radiologists have limited awareness of the significance of these findings. These and other studies [64-66] triggered substantial efforts by the International Osteoporosis Foundation and the European Society of Skeletal Radiology to educate radiologists on diagnosing osteoporotic fractures. Web-based teaching materials are now available to raise awareness and teach radiologists how to correctly classify osteoporotic vertebral fractures (http://www.iofbonehealth. org/vfi/index-flash.html).

Of central importance for the diagnosis and grading of osteoporotic fractures is the semiquantitative grading system that was developed by Genant et al. [67]. According to this score, a vertebral deformity of T4-L4 of more than $20 \%$ loss in height with an area of reduction in height of more than $10-20 \%$ is defined as a fracture. This approach has been applied and tested extensively in a number of clinical drug trials and epidemiological studies [68, 69]. Four grades are differentiated: grade $0=$ no fracture, grade $1=$ mild fracture (reduction in vertebral height $20-25 \%$, compared to adjacent normal vertebrae), grade $2=$ moderate fracture

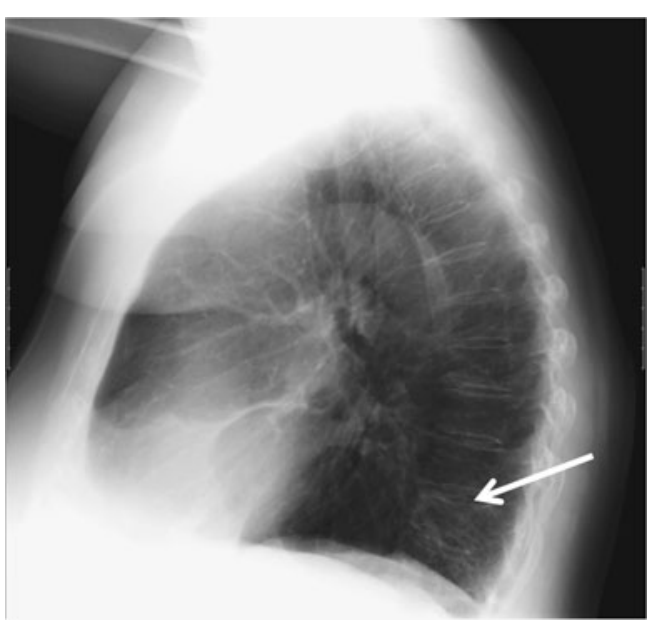

Fig. 6 Lateral chest radiograph in a postmenopausal woman showing an osteoporotic fracture deformity of a lower thoracic vertebral body (arrow), which could be missed or inadequately documented as a sign of osteoporosis as demonstrated by previous studies [64-66]. Figure from reference [70] 
(reduction in height $25-40 \%$ ), and grade $3=$ severe fracture (reduction in height more than 40\%) (Fig. 7). Wedge-shaped and biconcave fracture deformities are most common in osteoporosis, while posterior vertebral fractures should always raise concerns of neoplastic/ metastatic vertebral body infiltration [70].

Recent efforts have focused on using standard MD-CT as a tool to diagnose osteoporotic vertebral fractures [71, 72] using routine sagittal reconstructions, as these are missed on axial sections. In a recent study, Muller et al. [71] analyzed routine abdominal or thoracoabdominal MDCTs in 112 postmenopausal women. Axial images and sagittal reformations were analyzed separately by two radiologists in consensus and compared to the official radiology reports. In 27 patients osteoporotic vertebral deformities were found on the sagittal reformations, but only 6 of these were shown in the axial images and none of these were diagnosed in the official radiology report. The authors concluded that sagittal reformations of standard MD-CT images provide important additional information on osteoporotic vertebral deformities and should be part of standard CT analyses. In a similar study, Williams et al. [72] found that 38 of $192(19.8 \%)$ patients had moderate to severe vertebral fractures and in only $5(13 \%)$ patients were these correctly reported in the initial CT reports. Consequently they stated that incidental osteoporotic vertebral fractures are underreported on CT and that sagittal reformations are strongly recommended to improve the detection rate.

Increasing awareness regarding correctly diagnosing osteoporotic insufficiency fractures with MRI and separating them from other differential diagnoses was also the goal of several recent publications [73-78]. Cabarrus et al. [74] compared CT and MRI in diagnosing pelvic insufficiency fractures and found that only 89 of 129 (69\%) fractures in 34 of $64(53 \%)$ patients were correctly diagnosed with CT, while MRI demonstrated 128 of 129 (99\%) fractures in 63 of $64(98 \%)$ subjects. In particular, sacral insufficiency fractures were not as well demonstrated by CT (Fig. 8). These investigators also found that two or more insufficiency fractures were frequently present in the same patient and that insufficiency fractures were often associated with malignant disease. It is of critical importance that radiologists not misinterpret insufficiency fractures as malignancies and thus misguide patient management, which may result in dangerous and costly interventional procedures.

In addition, recent publications have provided evidence that what was previously defined as spontaneous osteonecrosis of the knee (SONC) is in fact an insufficiency fracture $[75,76]$; this new concept again may alter patient management as it has been shown that osteoporosis-specific therapies will reduce the number of future insufficiency fractures. Similar findings were also presented for the hip, questioning the diagnosis of avascular necrosis in older patients and demonstrating histological signs of insufficiency fractures instead [77-79].

\section{Osteoarthritis - from WORMS to cartilage matrix imaging}

Conventional radiographs were the standard for diagnosing osteoarthritis (OA) over many years, and the radiographbased Kellgren-Lawrence Scale is still a standard of reference for grading osteoarthritis [80]. In 2003, however, a study assessing MR findings in OA [81] demonstrated that MRI gives substantial information beyond radiographs as it also demonstrates degenerative changes in the cartilage, menisci, ligaments, bone marrow, and synovial tissue. In particular, morphological evaluation of the cartilage has subsequently gained substantial significance as a biomarker for the evaluation of osteoarthritis.

Corresponding to the Kellgren-Lawrence scale, a semiquantitative scoring system for knee MRIs was developed

Fig. 7 Semi-quantitative grading system developed by Genant et al. [67] and currently used as a standard to diagnose and grade osteoporotic fractures. Grade $1=$ mild fracture (reduction in vertebral height $20-25 \%$, compared to adjacent normal vertebrae), grade $2=$ moderate fracture (reduction in height $25-40 \%$ ), and grade $3=$ severe fracture (reduction in height more than $40 \%$ ). Figure from reference [70]
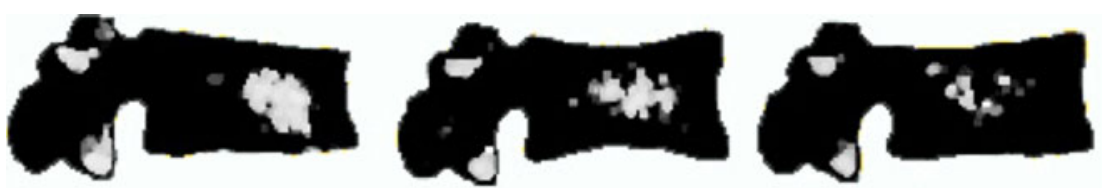

Grade 1
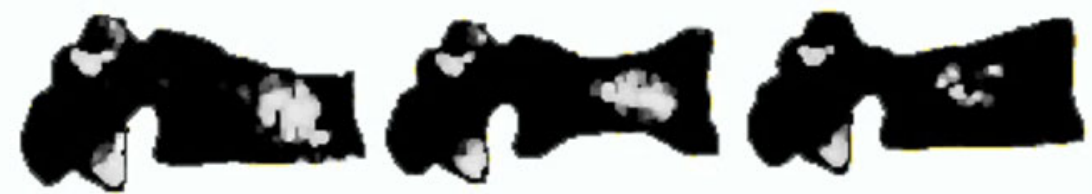

Grade 2
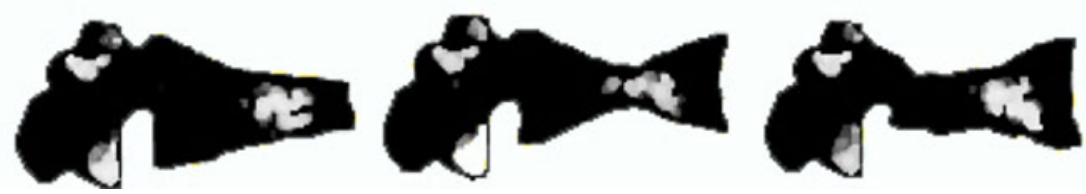

Grade 3 

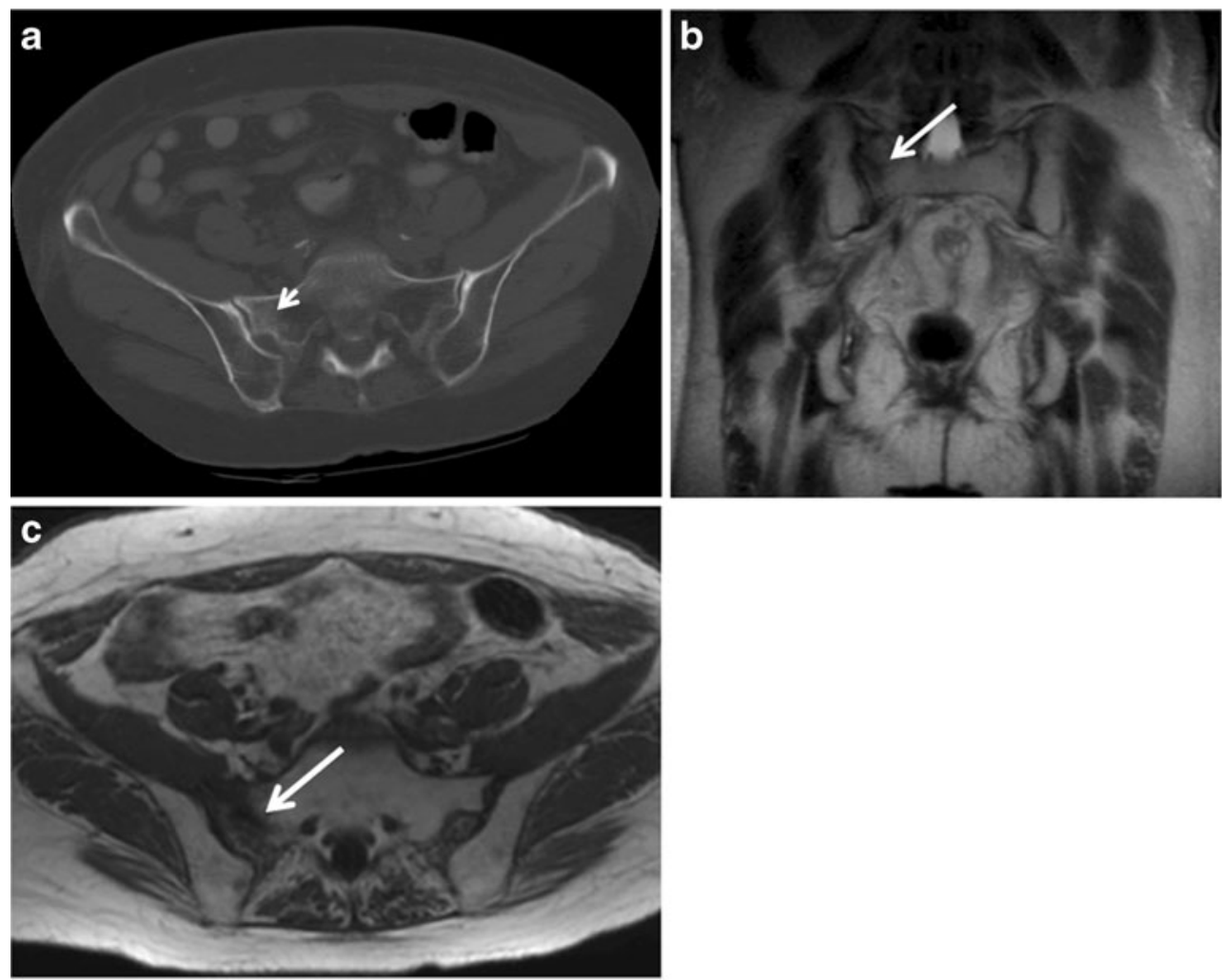

Fig. 8 Axial CT image (a), coronal T2-weighted (b), and axial (c) T1weighted fast spin echo images of the sacrum in a postmenopausal woman with a right sacral insufficiency fracture. While the fracture is shown well in the MR images (arrows) only a subtle area of increased sclerosis (small arrow) is shown on the CT image, but no definite fracture to grade $\mathrm{OA}$, as required for scientific studies analyzing the progression of $\mathrm{OA}$ and the impact of interventions. The Whole-Organ Magnetic Resonance Imaging Score (WORMS) was published in 2004 by Peterfy et al. [82]. Using WORMS, cartilage morphology is scored from 0 to 6 in 14 anatomical knee regions (Fig. 9): a score of 0 is defined as normal cartilage thickness and signal; 1 as normal thickness but increased signal on T2- or intermediate-weighted fast spin echo (FSE) images; 2 as a solitary, focal, partial-thickness defect $\leq 1 \mathrm{~cm}$ in width; 2.5 as a solitary, focal, full-thickness defect $\leq 1 \mathrm{~cm} ; 3$ as multiple areas of partial-thickness loss or as a grade 2 lesion $>1 \mathrm{~cm}$, with areas of preserved thickness; 4 as diffuse, $>75 \%$, partial-thickness loss; 5 as multiple areas of fullthickness cartilage loss, or a full-thickness lesion $>1 \mathrm{~cm}$, with areas of partial-thickness loss; and 6 as diffuse, $>75 \%$ full-thickness loss. Bone marrow edema pattern and subchondral cyst formation are each scored 0-3: a score of 0 is defined as normal; 1 as mild, covering $<25 \%$ of the anatomical region; 2 as moderate, covering $25-50 \%$ of the region; and 3 as severe, covering $>50 \%$ of the region. Osteophytes are graded from 0 to 7 using the following scale: $0=$ none, $1=$ equivocal, $2=$ small, $3=$ small to moderate, $4=$ moderate, $5=$ moderate to large, $6=$ large, and $7=$ very large. Ligaments are graded as intact (0) or torn (1). The anterior horn, body segment, and posterior horn of the medial and lateral menisci are graded separately from 0 to 4 based on both the sagittal and coronal images: $0=$ intact, $1=$ minor radial tear or parrot-beak tear, $2=$ non-displaced tear or prior surgical repair, $3=$ displaced tear or partial resection, $4=$ complete maceration/destruction or complete resection. Figures 10 and 11 show MR images of the knee with various WORMS grades.

In 2008 an additional score, the Boston Leeds Osteoarthritis Score (BLOKS), was established to grade MRI studies of the knee [83] and demonstrated good reliability. It was also shown that BLOKS may have superior validity for one of the components compared to WORMS, as Hunter et al. [83] found that maximum bone marrow lesion size on the BLOKS scale had a positive linear relation with visual analogue scale pain while the WORMS scale did not and that the association between baseline bone marrow lesion score with cartilage loss was stronger for the BLOKS than for the WORMS scale.

However, it should be noted that these grading systems focus on morphological abnormalities associated with relatively advanced disease. Given the fact that cartilage does not regenerate and the degenerative cartilage defects will not heal, diagnosis of degeneration should be made before irreversible cartilage loss has occurred. Efforts have 


\section{Grade 1}

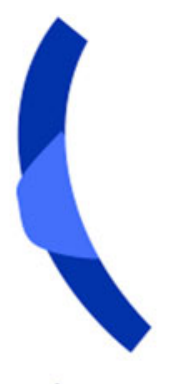

Grade 4

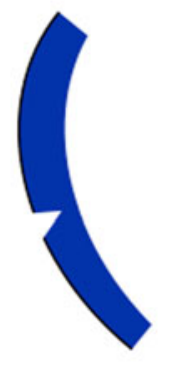

Grade 3

\section{Grade 4}

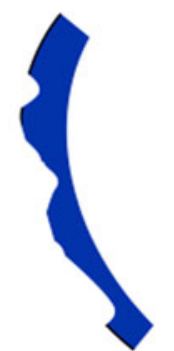

Grade 5

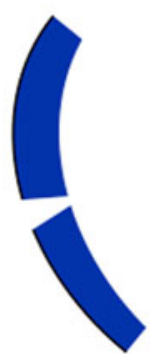

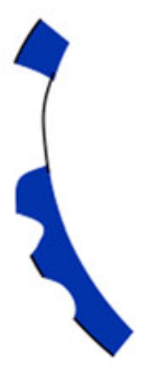

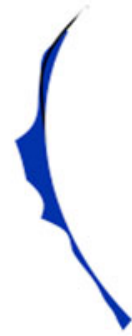

Fig. 9 Schematic of cartilage WORMS grades (see detailed description in the text)

therefore been undertaken to use MR techniques to diagnose cartilage degeneration at the biochemical/molecular level before morphological damage is evident. Three techniques have been developed that serve as surrogate markers for

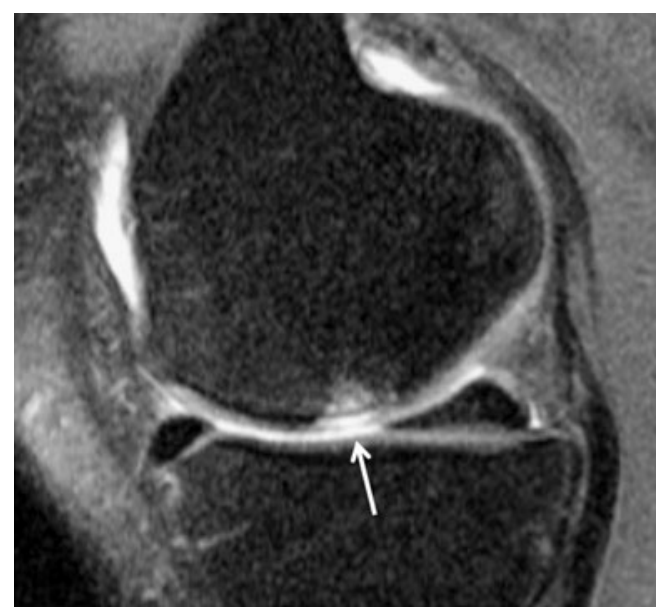

Fig. 10 Sagittal intermediate-weighted fast spin echo MR sequence of the medial knee compartment with a focal, full thickness, WORMS grade 2.5 lesion at the medial femoral condyle (arrow) with underlying grade 1 bone marrow edema pattern

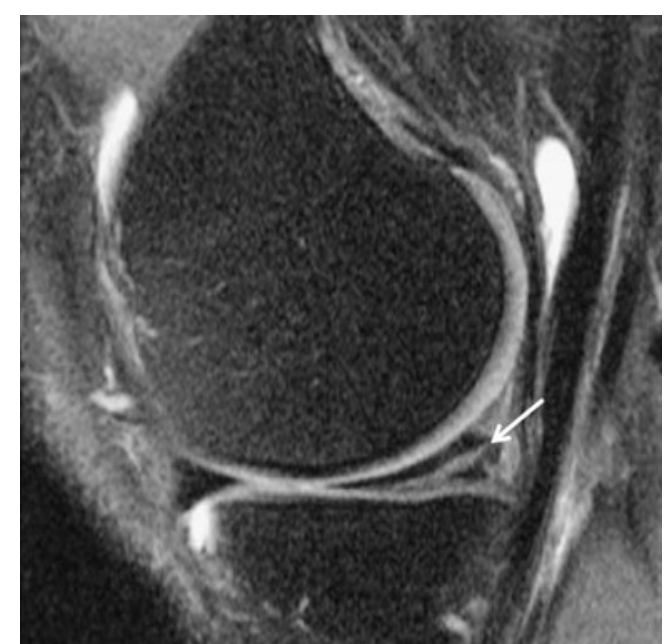

Fig. 11 Sagittal intermediate-weighted fast spin echo MR sequence of the medial knee compartment demonstrating a horizontal, grade 2 tear of the medial meniscus posterior horn without deformity (arrow). Also note small popliteal cyst

cartilage biochemical composition: delayed gadoliniumenhanced MRI of cartilage (dGEMRIC), and T1rho and T2 relaxation time measurements.

\section{dGEMRIC}

Cartilage consists of approximately $70 \%$ water and the remainder predominantly of type II collagen fibers and glycosaminoglycans (GAG). These GAG macromolecules contain negative charges that attract sodium ions $\left(\mathrm{NA}^{+}\right)$. One of the most frequently used MRI contrast agents, Gd-DTPA ${ }^{2-}$ (Magnevist, Bayer Healthcare), also has negative charges and will therefore not penetrate cartilage in areas of high GAG concentrations. In fact it will be distributed in higher concentrations in areas with lower GAG concentration and thus pathologic cartilage composition. Gd-DTPA ${ }^{2-}$ concentrations in cartilage can be quantified, and this technique has been defined as delayed gadolinium-enhanced MRI of cartilage (dGEMRIC). Initial studies have shown that the dGEMRIC measurement of GAG corresponds to the true GAG concentration as measured with biochemistry and histology [84-86]. This technique has also been used in a number of clinical studies, and variations of this measurement have been shown in patients with osteoarthritis, trials of autologous chondrocyte implants, and subjects with sedentary lifestyle versus those taking regular exercise [87-90]. Williams et al. examined 31 patients with knee OA with a dGEMRIC protocol at $1.5 \mathrm{~T}$ and full-limb knee radiographs to assess alignment [90]. These authors found that compartments of the knee joint without joint space narrowing had a higher dGEMRIC index than those with any level of narrowing (mean 408 vs. $365 \mathrm{~ms} ; P=0.001$ ). In knees with 
Fig. 12 Cartilage T2 maps of the medial femoral cartilage in a healthy individual (a) and a subject with early OA (b). Note higher $\mathrm{T} 2$ values in $\mathbf{b}$ indicating higher water content and degeneration of the collagen matrix
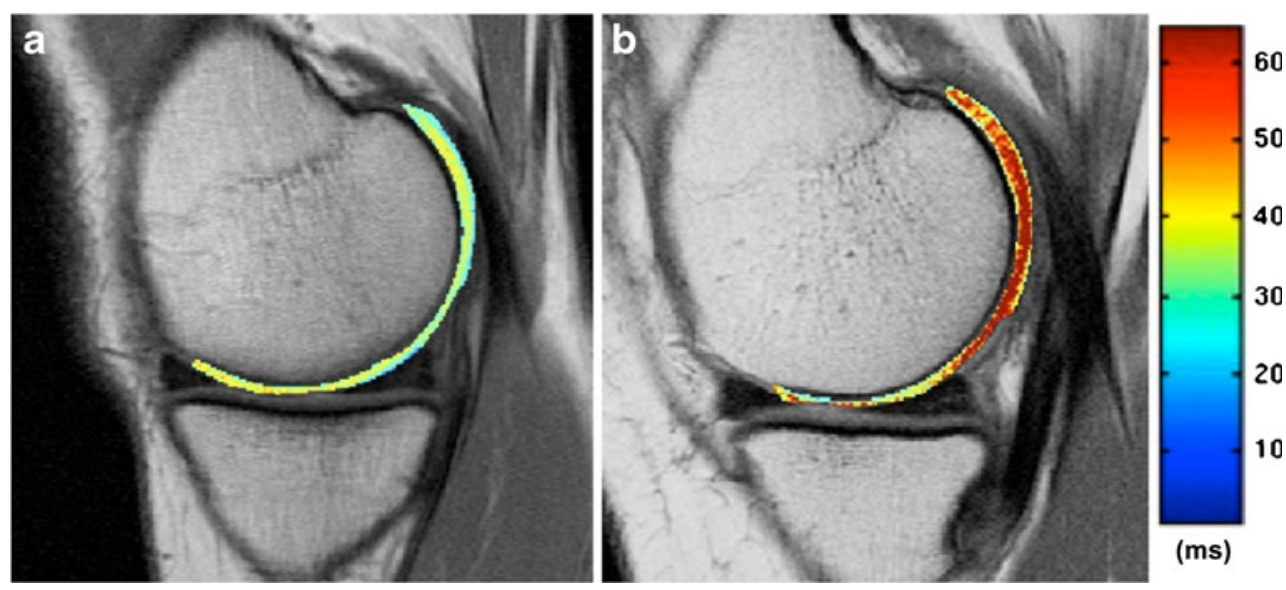

one unnarrowed (spared) and one narrowed (diseased) compartment, the dGEMRIC index was greater in the spared versus the diseased compartment (mean 395 vs. $369 \mathrm{~ms} ; P=$ 0.001). Valgus-aligned knees tended to have lower dGEMRIC values laterally, and varus-aligned knees tended to have lower dGEMRIC values medially. The authors concluded that these quantitative findings may have an important role in evaluating early osteoarthritis.

\section{$\mathrm{T} 2$ relaxation time measurements}

Another approach that has been used to measure cartilage composition is T2 mapping. In an early study, Dardzinski et al. examined the spatial variation of in vivo cartilage $\mathrm{T} 2 \mathrm{in}$ young asymptomatic adults and found a reproducible pattern of increasing $\mathrm{T} 2$ that was proportional to the known spatial variation in cartilage water and was inversely proportional to the distribution of proteoglycans [91]. These authors postulated that the regional T2 differences were secondary to the restricted mobility of cartilage water within an anisotropic solid matrix. Thus measurement of the spatial distribution of the T2 reflecting areas of increased and decreased water content may be used to quantify cartilage degeneration before morphologic changes are apparent. Subsequent studies have also suggested that T2 relaxation time measurements are sensitive to the collagen architecture [92, 93]. In 2004 Dunn et al. published a study where they analyzed 55 subjects who were categorized with radiography as healthy $(n=7)$ or as having mild OA $(n=20)$ or severe OA $(n=28)$ [94]. These authors found that healthy subjects had mean T2 values of $32.1-35.0 \mathrm{~ms}$, while patients with mild and severe OA had mean T2 values of $34.4-41.0 \mathrm{~ms}$. All cartilage compartments except the lateral tibia showed significant $(P<0.05)$ increases in $\mathrm{T} 2$ relaxation time between healthy and diseased knees. Correlation of $\mathrm{T} 2$ values with clinical symptoms and cartilage morphology was found predominantly in medial compartments. Similar results were found by Stahl et al. differentiating healthy females and females with early OA [95], suggesting that T2 measurements may be particularly well suited to diagnose $\mathrm{T} 2$ alterations in early stages of cartilage degeneration. Recently Stehling et
Fig. 13 T1rho maps of the patella and trochlea in two nonsymptomatic, physically active subjects. No cartilage defects were found in subject a with lower T1rho values, while a diffuse increase in T1rho in subject $\mathbf{b}$ was associated with cartilage defects. Figure obtained from reference [101]
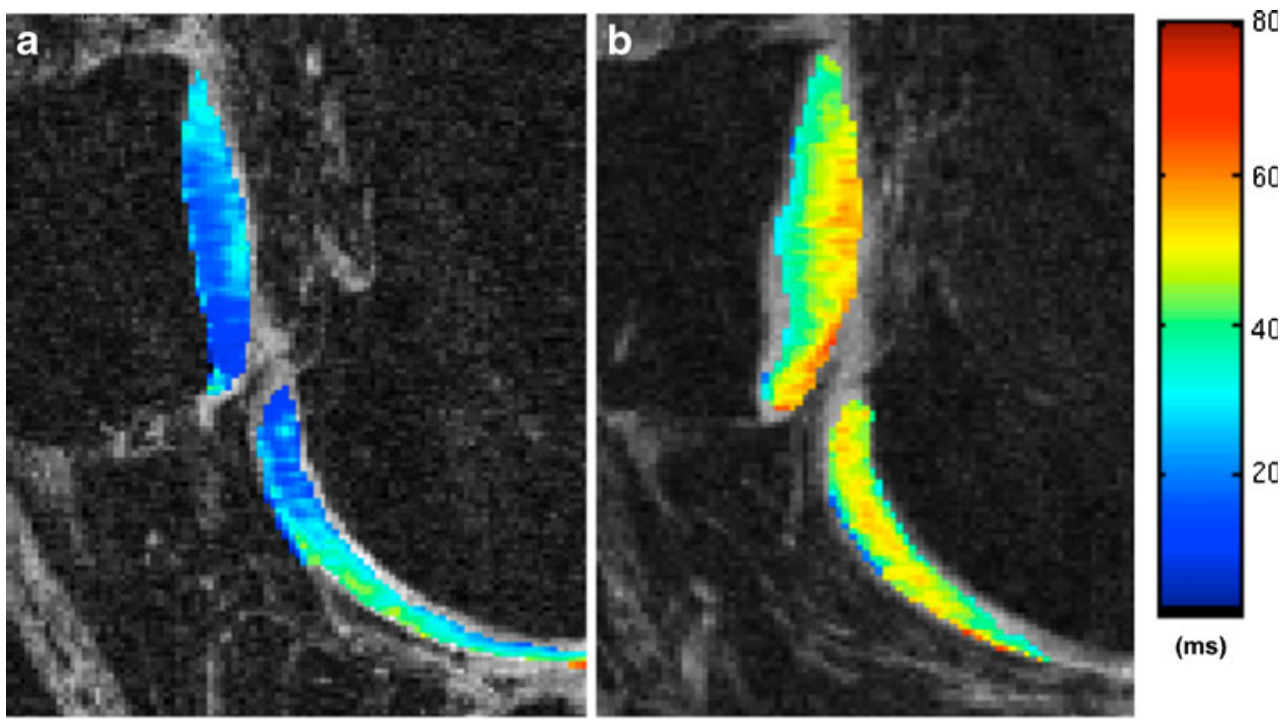

(ms) 
al. studied patella cartilage $\mathrm{T} 2$ relaxation time in relation to physical activity levels in asymptomatic subjects from the Osteoarthritis Initiative (OAI) incidence cohort. They found that individuals with high activity levels had significantly higher T2 values $(48.7 \pm 4.35$ vs $45.8 \pm 3.93 \mathrm{~ms} ; P<0.001)$ than did subjects with low activity levels and that these individuals also had a higher prevalence and grade of knee abnormalities demonstrated on knee MRIs [96]. Figure 12 shows cartilage T2 maps of the medial femoral cartilage in a healthy individual and a subject with early OA, impressively documenting differences in $\mathrm{T} 2$ values. In addition to hyaline cartilage, T2 maps have also been used to quantify biochemical composition of the menisci, and significant differences in meniscus $\mathrm{T} 2$ between healthy individuals and subjects with early and advanced OA have been demonstrated [97].

\section{T1rho measurements}

The third parameter that has been proposed to measure cartilage biochemical composition is T1rho-relaxation mapping. $\mathrm{T}(1 \mathrm{rho})$ describes the spin-lattice relaxation in the rotating frame, and changes in the extracellular matrix of cartilage, such as the loss of GAG, may be reflected in measurements of T1rho due to less restricted motion of water protons. Preliminary results have demonstrated the in vivo feasibility of quantifying early biochemical changes in symptomatic osteoarthritis subjects employing T1rho-weighted MRI on a $1.5 \mathrm{~T}$ clinical scanner $[98,99]$. In an early clinical study, Li et al. examined 10 healthy volunteers, and 9 osteoarthritis patients at $3 \mathrm{~T}$ and found a significant difference $(P=$ $0.002)$ in the average T1rho within patellar and femoral cartilage between controls $(45.04 \pm 2.59 \mathrm{~ms})$ and osteoarthritis patients $(53.06 \pm 4.60 \mathrm{~ms})$ [100]. A significant correlation was found between $\mathrm{T} 1$ rho and $\mathrm{T} 2$ relaxation measurements; however, the difference in T2 was not significant between controls and osteoarthritis patients. These initial results suggested that $\mathrm{T} 1$ rho relaxation times may be a promising clinical tool for osteoarthritis detection and treatment monitoring.

Recently Stahl et al. [101] studied T1rho relaxation times and the degree of focal cartilage abnormalities in physically active and sedentary healthy individuals. These investigators found that active subjects with and without focal cartilage abnormalities had different T1rho composition of cartilage and concluded that T1rho could be a parameter suited to identify active healthy subjects at higher risk for developing cartilage pathology (Fig. 13). Bolbos et al. quantitatively assessed the cartilage overlying bone contusions with bone marrow edema pattern in knees with anterior cruciate ligament (ACL) tears using T1rho mapping techniques and found significantly increased T1rho values at the posterior lateral tibia in cartilage overlying bone marrow edema pattern when compared with surrounding cartilage. They concluded that cartilage abnormalities are already present following initial ACL injuries over the posterior lateral tibia and that quantitative MRI can allow critical evaluation of these lesions including early diagnosis and monitoring after therapy [102]. T1rho recently has been applied to the study of the meniscus with promising results in assessing degenerative and post-traumatic changes [97, 103]. In summary T1rho has been shown to be a promising biomarker to assess biochemical changes related to degenerative and post-traumatic disease of the menisci and the hyaline cartilage of the knee.

\section{Conclusion}

A review of the literature of the last three decades indicates that substantial progress in diagnostic techniques to diagnose and monitor osteoporosis and osteoarthritis has been made. We have moved from qualitative techniques increasingly to quantitative techniques, and we have achieved higher spatial resolutions to quantify bone structure while also developing new imaging techniques to quantify the biochemical composition of bone and cartilage. These techniques have impacted and will in the future increasingly impact patient management to prevent, treat, and monitor osteoporosis and osteoarthritis.

Acknowledgments The Founders Medal of the International Skeletal Society (ISS) was awarded to Harry K. Genant, Professor Emeritus, UCSF, San Francisco, CA, USA at the ISS annual meeting in Washington DC, USA in 2009. The recipient was honored for contributions made to the ISS and in advancing the field of musculoskeletal science particularly in the field of imaging of osteoporosis and osteoarthritis. This review is largely based on the lecture of the same title given in honor of the 2009 Founders Medal recipient. The International Skeletal Society was founded 37 years ago.

Open Access This article is distributed under the terms of the Creative Commons Attribution Noncommercial License which permits any noncommercial use, distribution, and reproduction in any medium, provided the original author(s) and source are credited.

\section{References}

1. Genant HK, Boyd DP. Quantitative bone mineral analysis using dual energy computed tomography. Invest Radiol. 1977;12:54551.

2. Genant HK, Cann CE, Pozzi-Mucelli RS, Kanter AS. Vertebral mineral determination by quantitative computed tomography: clinical feasibility and normative data. J Comput Assist Tomogr. 1983;7:554.

3. Bousson V, Le Bras A, Roqueplan F, Kang Y, Mitton D, Kolta S, et al. Volumetric quantitative computed tomography of the proximal 
femur: relationships linking geometric and densitometric variables to bone strength. Role for compact bone. Osteoporos Int. 2006;17 (6):855-64.

4. Kalender W, Felsenberg D, Louis O, Lopez P, Klotz E, Osteaux M, et al. Reference values for trabecular and cortical vertebral bone density in single and dual-energy quantitative computed tomography. Eur J Radiol. 1989;9:75-80.

5. Cann C, Genant H. Precise measurement of vertebral mineral content using computed tomography. J Comput Assist Tomogr. 1980;4:493-500.

6. Kalender W, Brestowsky H, Felsenberg D. Bone mineral measurements: automated determination of the midvertebral CT section. Radiology. 1988;168:219-21.

7. Carpenter RD, Beaupre GS, Lang TF, Orwoll ES, Carter DR. New QCT analysis approach shows the importance of fall orientation on femoral neck strength. J Bone Miner Res. 2005;20(9):1533-42.

8. Farhat GN, Cauley JA, Matthews KA, Newman AB, Johnston J, Mackey R, et al. Volumetric BMD and vascular calcification in middle-aged women: the Study of Women's Health Across the Nation. J Bone Miner Res. 2006;21(12):1839-46.

9. Lang T, Li J, Harris S, Genant H. Assessment of vertebral bone mineral density using volumetric quantitative CT. J Comput Assist Tomogr. 1999;23:130-7.

10. Lang TF, Keyak JH, Heitz MW, Augat P, Lu Y, Mathur A, et al. Volumetric quantitative computed tomography of the proximal femur: precision and relation to bone strength. Bone. 1997;21 (1):101-8

11. Bohr H, Schaadt O. Bone mineral content of femoral bone and the lumbar spine measured in women with fracture of femoral neck by dual photon absorptiometry. Clin Orthop. 1983;179:240-5.

12. Borders J, Kerr E, Sartoris DJ, Stein JA, Ramos E, Moscona AA, et al. Quantitative dual energy radiographic absorptiometry of the lumbar spine: in vivo comparison with dual-photon absorptiometry. Radiology. 1989;170:129-31.

13. The Writing Group for the International Society for Clinical Densitometry (ISCD) Position Development Conference. Position statement: diagnosis of osteoporosis in men, premenopausal women, and children. J Clin Densitom. 2004;7(1):17-26.

14. The Writing Group for the International Society for Clinical Densitometry (ISCD) Position Development Conference. Position statement: introduction, methods, and participants. J Clin Densitom. 2004;7(1):13-16.

15. The Writing Group for the International Society for Clinical Densitometry (ISCD) Position Development Conference. Position statement : executive summary. J Clin Densitom. 2004; 7(1):7-12.

16. Cummings SR, Melton LJ. Epidemiology and outcomes of osteoporotic fractures. Lancet. 2002;359(9319):1761-7.

17. Taylor BC, Schreiner PJ, Stone KL, Fink HA, Cummings SR, Nevitt MC, et al. Long-term prediction of incident hip fracture risk in elderly white women: study of osteoporotic fractures. J Am Geriatr Soc. 2004;52(9):1479-86.

18. Theodorou D, Theodorou S. Dual-energy X-ray absorptiometry in clinical practice: application and interpretation of scans beyond the numbers. Clin Imaging. 2002;26:43-9.

19. Ammann P, Rizzoli R. Bone strength and its determinants. Osteoporos Int. 2003;14 Suppl 3:S13-8.

20. Consensus Development Conference: diagnosis, prophylaxis, and treatment of osteoporosis. Am J Med. 1993;94:646-50.

21. NIH Consensus Development Panel on Osteoporosis Prevention, Diagnosis, and Therapy. Osteoporosis prevention, diagnosis, and therapy. JAMA. 2001;285:785-795.

22. Majumdar S, Lin J, Link T, Millard J, Augat P, Ouyang X, et al. Fractal analysis of radiographs: assessment of trabecular bone structure and prediction of elastic modulus and strength. Med Phys. 1999;26(7):1330-40.

23. Ouyang X, Majumdar S, Link TM, Lu Y, Augat P, Lin J, et al. Morphometric texture analysis of spinal trabecular bone structure assessed using orthogonal radiographic projections. Med Phys. 1998;25(10):2037-45.

24. Veenland J, Link T, Konermann W, Meier N, Grashuis J, Gelsema E. Unraveling the role of structure and density in determining vertebral bone strength. Calcif Tissue Int. 1997; 61:474-9.

25. Benhamou C, Lespessailes E, Touliere D, Jacquet G, Harba R, Jennane R. Fractal evaluation of trabecular bone microarchitecture: comparative study of calcaneus and ultradistal radius. J Bone Miner Res. 1993;8:263.

26. Caligiuri P, Giger ML, Favus M. Multifractal radiographic analysis of osteoporosis. Med Phys. 1994;21(4):503-8.

27. Geraets W, van der Stelt P, Netelenbos C, Elders P. A new method for automatic recognition of the radiographic trabecular pattern. J Bone Miner Res. 1990;5:227-32.

28. Ishida T, Kazuya Y, Takigawa A, Kariya K, Itoh H. Trabecular pattern analysis using fractal dimension. Jpn J Appl Phys 1993;32(4):1867-71.

29. Lespessailles E, Roux J, Benhamou C, Arlot M, Eynard E, Harba $\mathrm{R}$, et al. Fractal analysis of bone texture on os calcis radiographs compared with trabecular microarchitecture analyzed by histomorphometry. Calcif Tissue Int. 1998;63:121-5.

30. Pulkkinen P, Partanen J, Jalovaara P, Jamsa T. Combination of bone mineral density and upper femur geometry improves the prediction of hip fracture. Osteoporos Int. 2004;15(4):274-80.

31. Laval-Jeantet A, Chevalier F, Pellot C, Bergot C. CT imaging and the quest for information on the vertebral structure. Seventh International Workshop on Bone Densitometry; 1989 September 17-21; Rancho Mirage, CA, USA.

32. Link T, Majumdar S, Lin J, Augat P, Gould R, Newitt D, et al. Assessment of trabecular structure using high-resolution CT images and texture analysis. J Comput Assist Tomogr. 1998; 22:15-24.

33. Waldt S, Meier N, Renger B, Lenzen H, Fiebich M, Rummeny EJ, et al. The texture-analysis of high-resolution computed tomograms as an additional procedure in osteoporosis diagnosis: in-vitro studies on vertebral segments. Rofo. 1999;171(2):136-42.

34. Chevalier F, Laval-Jeantet A, Laval-Jeantet M, Bergot C. CT image analysis of the vertebral trabecular network in vivo. Calcif Tissue Int. 1992;51:8-13.

35. Diederichs G, Link T, Marie K, Huber M, Rogalla P, Burghardt A, et al. Feasibility of measuring trabecular bone structure of the proximal femur using 64-slice multidetector computed tomography in a clinical setting. Calcif Tissue Int. 2008;83(5):332-41.

36. Diederichs G, Link TM, Kentenich M, Schwieger K, Huber MB, Burghardt AJ, et al. Assessment of trabecular bone structure of the calcaneus using multi-detector CT: correlation with microCT and biomechanical testing. Bone. 2009;44(5):976-83.

37. Issever AS, Link TM, Kentenich M, Rogalla P, Burghardt AJ, Kazakia GJ, et al. Assessment of trabecular bone structure using MDCT: comparison of 64- and 320-slice CT using HR-pQCT as the reference standard. Eur Radiol. 2010;20(2):458-68.

38. Issever AS, Link TM, Kentenich M, Rogalla P, Schwieger K, Huber $\mathrm{MB}$, et al. Trabecular bone structure analysis in the osteoporotic spine using a clinical in vivo setup for 64-slice MDCT imaging: comparison to microCT imaging and microFE modeling. J Bone Miner Res. 2009;24(9):1628-37.

39. Link TM, Vieth V, Stehling C, Lotter A, Beer A, Newitt D, et al. High-resolution MRI vs multislice spiral CT: which technique depicts the trabecular bone structure best? Eur Radiol. 2003;13 (4):663-71.

40. Graeff C, Timm W, Nickelsen TN, Farrerons J, Marin F, Barker $\mathrm{C}$, et al. Monitoring teriparatide-associated changes in vertebral 
microstructure by high-resolution $\mathrm{CT}$ in vivo: results from the EUROFORS study. J Bone Miner Res. 2007;22(9):1426-33.

41. Ito M, Ikeda K, Nishiguchi M, Shindo H, Uetani M, Hosoi T, et al. Multi-detector row CT imaging of vertebral microstructure for evaluation of fracture risk. J Bone Miner Res. 2005;20 (10):1828-36.

42. Burrows M, Liu D, McKay H. High-resolution peripheral QCT imaging of bone micro-structure in adolescents. Osteoporos Int. 2009;21(3):515-20.

43. Boutroy S, Bouxsein ML, Munoz F, Delmas PD. In vivo assessment of trabecular bone microarchitecture by highresolution peripheral quantitative computed tomography. J Clin Endocrinol Metab. 2005;90(12):6508-15.

44. Burghardt AJ, Dais KA, Masharani U, Link TM, Majumdar S. In vivo quantification of intra-cortical porosity in human cortical bone using hr-pQCT in patients with type II diabetes. J Bone Miner Res. 2008;23:S450.

45. Davis KA, Burghardt AJ, Link TM, Majumdar S. The effects of geometric and threshold definitions on cortical bone metrics assessed by in vivo high-resolution peripheral quantitative computed tomography. Calcif Tissue Int. 2007;81(5):364-71.

46. Kazakia GJ, Hyun B, Burghardt AJ, Krug R, Newitt DC, de Papp AE, et al. In vivo determination of bone structure in postmenopausal women: a comparison of HR-pQCT and highfield MR imaging. J Bone Miner Res. 2008;23(4):463-74.

47. Cortet B, Boutry N, Dubois P, Bourel P, Cotten A, Marchandise $X$. In vivo comparison between computed tomography and magnetic resonance image analysis of the distal radius in the assessment of osteoporosis. J Clin Densitom. 2000;3:15-26.

48. Link T, Lotter A, Beyer F, Christiansen S, Newitt D, Lu Y, et al. Post-cardiac transplantation changes in calcaneal trabecular bone structure: a magnetic resonance imaging study. Radiology. 2000;217:855-62.

49. Link TM, Majumdar S, Augat P, Lin JC, Newitt D, Lu Y, et al. In vivo high resolution MRI of the calcaneus: differences in trabecular structure in osteoporosis patients. J Bone Miner Res. 1998;13(7):1175-82.

50. Majumdar S, Link T, Augat P, Lin J, Newitt D, Lane N, et al. Trabecular bone architecture in the distal radius using MR imaging in subjects with fractures of the proximal femur. Osteoporos Int. 1999;10:231-9.

51. Wehrli F, Gomberg B, Saha P, Song H, Hwang S, Snyder P. Digital topological analysis of in vivo magnetic resonance microimages of trabecular bone reveals structural implications of osteoporosis. J Bone Miner Res. 2001;16:1520-31.

52. Wehrli FW, Leonard MB, Saha PK, Gomberg BR. Quantitative high-resolution magnetic resonance imaging reveals structural implications of renal osteodystrophy on trabecular and cortical bone. J Magn Reson Imaging. 2004;20(1):83-9.

53. Chesnut CH 3rd, Majumdar S, Newitt DC, Shields A, Van Pelt J, Laschansky E, et al. Effects of salmon calcitonin on trabecular microarchitecture as determined by magnetic resonance imaging: results from the QUEST study. J Bone Miner Res. 2005;20 (9):1548-61.

54. Benito M, Gomberg B, Wehrli FW, Weening RH, Zemel B, Wright $\mathrm{AC}$, et al. Deterioration of trabecular architecture in hypogonadal men. J Clin Endocrinol Metab. 2003;88(4):1497-502.

55. Phan CM, Matsuura M, Bauer JS, Dunn TC, Newitt D, Lochmueller EM, et al. Trabecular bone structure of the calcaneus: comparison of MR imaging at 3.0 and $1.5 \mathrm{~T}$ with micro-CT as the standard of reference. Radiology. 2006;239 (2):488-96.

56. Rahmer J, Bornert P, Groen J, Bos C. Three-dimensional radial ultrashort echo-time imaging with T2 adapted sampling. Magn Reson Med. 2006;55(5):1075-82.
57. Techawiboonwong A, Song HK, Wehrli FW. In vivo MRI of submillisecond $\mathrm{T}(2)$ species with two-dimensional and threedimensional radial sequences and applications to the measurement of cortical bone water. NMR Biomed. 2008;21(1):59-70.

58. Davies KM, Stegman MR, Heaney RP, Recker RR. Prevalence and severity of vertebral fracture: the Saunders County Bone Quality Study. Osteoporos Int. 1996;6(2):160-5.

59. Johansson C, Mellstrom D, Rosengren K, Rundgren A. Prevalence of vertebral fractures in 85-year-olds. Radiographic examination of 462 subjects. Acta Orthop Scand. 1993;64 (1):25-7.

60. Nevitt MC, Ettinger B, Black DM, Stone K, Jamal SA, Ensrud $\mathrm{K}$, et al. The association of radiographically detected vertebral fractures with back pain and function: a prospective study. Ann Intern Med. 1998;128(10):793-800.

61. Ensrud K, Thompson D, Cauley J, Nevitt M, Kado D, Hochberg $\mathrm{M}$, et al. Prevalent vertebral deformities predict mortality and hospitalization in older women with low bone mass. Fracture Intervention Trial Research Group. J Am Geriatr Soc. 2000;48 (3):241-9.

62. Melton LJ III, Atkinson EJ, Cooper C, O'Fallon WM, Riggs BL. Vertebral fractures predict subsequent fractures. Osteoporos Int. 1999;10:214-21.

63. Lindsay R, Silverman S, Cooper C, Hanley D, Barton I, Broy S, et al. Risk of new vertebral fracture in the year following a fracture. JAMA. 2001;285:320-3.

64. Gehlbach S, Bigelow C, Heimisdottir M, May S, Walker M, Kirkwood J. Recognition of vertebral fracture in a clinical setting. Osteoporos Int. 2000;11:577-82.

65. Kim N, Rowe BH, Raymond G, Jen H, Colman I, Jackson SA, et al. Underreporting of vertebral fractures on routine chest radiography. AJR Am J Roentgenol. 2004;182(2):297-300.

66. Mueller D, Isbary M, Boehm H, Bauer J, Rummeny E, Link T. Recognition of osteoporosis-related vertebral fractures on chest radiographs in postmenopausal women. RSNA; 2004 Nov 28Dec 04; Chicago.

67. Genant HK, Wu CY, van Kuijk C, Nevitt MC. Vertebral fracture assessment using a semiquantitative technique. J Bone Miner Res. 1993;8:1137-48.

68. Storm T, Thamsborg G, Steiniche T, Genant HK, Sorensen OH. Effect of intermittent cyclical etidronate therapy on bone mass and fracture rate in women with postmenopausal osteoporosis. $\mathrm{N}$ Engl J Med. 1990;322(18):1265-71.

69. Ettinger B, Block JE, Smith R, Cummings SR, Harris ST, Genant HK. An examination of the association between vertebral deformities, physical disabilities and psychosocial problems. Maturitas. 1988;10(4):283-96.

70. Link TM, Guglielmi G, van Kuijk C, Adams JE. Radiologic assessment of osteoporotic vertebral fractures: diagnostic and prognostic implications. Eur Radiol. 2005;15(8):1521-32.

71. Muller D, Bauer JS, Zeile M, Rummeny EJ, Link TM. Significance of sagittal reformations in routine thoracic and abdominal multislice CT studies for detecting osteoporotic fractures and other spine abnormalities. Eur Radiol. 2008;18 (8):1696-702.

72. Williams AL, Al-Busaidi A, Sparrow PJ, Adams JE, Whitehouse RW. Under-reporting of osteoporotic vertebral fractures on computed tomography. Eur J Radiol. 2009;69(1):179-83.

73. Blake SP, Connors AM. Sacral insufficiency fracture. Br J Radiol. 2004;77(922):891-6.

74. Cabarrus MC, Ambekar A, Lu Y, Link TM. MRI and CT of insufficiency fractures of the pelvis and the proximal femur. AJR Am J Roentgenol. 2008;191(4):995-1001.

75. Kattapuram TM, Kattapuram SV. Spontaneous osteonecrosis of the knee. Eur J Radiol. 2008;67(1):42-8. 
76. Yamamoto T, Bullough PG. Spontaneous osteonecrosis of the knee: the result of subchondral insufficiency fracture. J Bone Joint Surg Am. 2000;82(6):858-66.

77. Yamamoto T, Iwamoto Y, Schneider R, Bullough PG. Histopathological prevalence of subchondral insufficiency fracture of the femoral head. Ann Rheum Dis. 2008;67(2):150-3.

78. Yamamoto T, Schneider R, Bullough PG. Subchondral insufficiency fracture of the femoral head: histopathologic correlation with MRI. Skeletal Radiol. 2001;30(5):247-54.

79. Yamamoto T, Schneider R, Bullough PG. Insufficiency subchondral fracture of the femoral head. Am J Surg Pathol. 2000;24(3):464-8.

80. Kellgren J, Lawrence J. Radiological assessment of osteoarthritis. Ann Rheum Dis. 1957;16:494-501.

81. Link TM, Steinbach LS, Ghosh S, Ries M, Lu Y, Lane N, et al. Osteoarthritis: MR imaging findings in different stages of disease and correlation with clinical findings. Radiology. 2003;226 (2):373-81.

82. Peterfy CG, Guermazi A, Zaim S, Tirman PF, Miaux Y, White D, et al. Whole-Organ Magnetic Resonance Imaging Score (WORMS) of the knee in osteoarthritis. Osteoarthritis Cartilage. 2004;12(3):177-90.

83. Hunter DJ, Lo GH, Gale D, Grainger AJ, Guermazi A, Conaghan PG. The reliability of a new scoring system for knee osteoarthritis MRI and the validity of bone marrow lesion assessment: BLOKS (Boston Leeds Osteoarthritis Knee Score). Ann Rheum Dis. 2008;67(2):206-11.

84. Bashir A, Gray ML, Boutin RD, Burstein D. Glycosaminoglycan in articular cartilage: in vivo assessment with delayed Gd(DTPA) (2-)-enhanced MR imaging. Radiology. 1997;205(2):551-8.

85. Bashir A, Gray ML, Hartke J, Burstein D. Nondestructive imaging of human cartilage glycosaminoglycan concentration by MRI. Magn Reson Med. 1999;41(5):857-65.

86. Trattnig S, Mlynarik V, Breitenseher M, Huber M, Zembsch A, Rand T, et al. MRI visualization of proteoglycan depletion in articular cartilage via intravenous administration of Gd-DTPA. Magn Reson Imaging. 1999;17:577-83.

87. Burstein D, Bashir A, Gray ML. MRI techniques in early stages of cartilage disease. Invest Radiol. 2000;35(10):622-38.

88. Gillis A, Bashir A, McKeon B, Scheller A, Gray ML, Burstein D. Magnetic resonance imaging of relative glycosaminoglycan distribution in patients with autologous chondrocyte transplants. Invest Radiol. 2001;36(12):743-8.

89. Williams A, Gillis A, McKenzie C, Po B, Sharma L, Micheli L, et al. Glycosaminoglycan distribution in cartilage as determined by delayed gadolinium-enhanced MRI of cartilage (dGEMRIC): potential clinical applications. AJR Am J Roentgenol. 2004;182 (1):167-72.

90. Williams A, Sharma L, McKenzie CA, Prasad PV, Burstein D. Delayed gadolinium-enhanced magnetic resonance imaging of cartilage in knee osteoarthritis: findings at different radiographic stages of disease and relationship to malalignment. Arthritis Rheum. 2005;52(11):3528-35.
91. Dardzinski BJ, Mosher TJ, Li S, Van Slyke MA, Smith MB. Spatial variation of T2 in human articular cartilage. Radiology. 1997;205(2):546-50.

92. Mosher TJ, Dardzinski BJ. Cartilage MRI T2 relaxation time mapping: overview and applications. Semin Musculoskelet Radiol. 2004;8(4):355-68.

93. Mosher TJ, Liu Y, Yang QX, Yao J, Smith R, Dardzinski BJ, et al. Age dependency of cartilage magnetic resonance imaging T2 relaxation times in asymptomatic women. Arthritis Rheum. 2004;50(9):2820-8.

94. Dunn TC, Lu Y, Jin H, Ries MD, Majumdar S. T2 relaxation time of cartilage at MR imaging: comparison with severity of knee osteoarthritis. Radiology. 2004;232(2):592-8.

95. Stahl R, Blumenkrantz G, Carballido-Gamio J, Zhao S, Munoz T, Hellio Le Graverand-Gastineau MP, et al. MRI-derived T2 relaxation times and cartilage morphometry of the tibio-femoral joint in subjects with and without osteoarthritis during a one-year follow-up. Osteoarthritis Cartilage. 2007;15:1225-34.

96. Stehling C, Liebl H, Krug R, Lane NE, Nevitt MC, Lynch J, et al. Patellar cartilage: $\mathrm{T} 2$ values and morphologic abnormalities at 3.0-T MR imaging in relation to physical activity in asymptomatic subjects from the Osteoarthritis Initiative. Radiology. 2010;254(2):509-20.

97. Rauscher I, Stahl R, Cheng J, Li X, Huber MB, Luke A, et al. Meniscal measurements of T1rho and T2 at MR imaging in healthy subjects and patients with osteoarthritis. Radiology. 2008;249(2):591-600.

98. Regatte RR, Akella SV, Borthakur A, Kneeland JB, Reddy R. In vivo proton MR three-dimensional T1rho mapping of human articular cartilage: initial experience. Radiology. 2003;229 (1):269-74.

99. Regatte RR, Akella SV, Wheaton AJ, Lech G, Borthakur A, Kneeland JB, et al. 3D-T1rho-relaxation mapping of articular cartilage: in vivo assessment of early degenerative changes in symptomatic osteoarthritic subjects. Acad Radiol. 2004;11 (7):741-9.

100. Li X, Han ET, Ma CB, Link TM, Newitt DC, Majumdar S. In vivo $3 \mathrm{~T}$ spiral imaging based multi-slice $\mathrm{T}$ (1rho) mapping of knee cartilage in osteoarthritis. Magn Reson Med. 2005;54 (4):929-36.

101. Stahl R, Luke A, Li X, Carballido-Gamio J, Ma CB, Majumdar S, et al. T1rho, T2 and focal knee cartilage abnormalities in physically active and sedentary healthy subjects versus early OA patients-a 3.0-Tesla MRI study. Eur Radiol. 2009;19(1):132-43.

102. Bolbos RI, Ma CB, Link TM, Majumdar S, Li X. In vivo T1rho quantitative assessment of knee cartilage after anterior cruciate ligament injury using 3 Tesla magnetic resonance imaging. Invest Radiol. 2008;43(11):782-8.

103. Bolbos RI, Link TM, Ma CB, Majumdar S, Li X. T1rho relaxation time of the meniscus and its relationship with T1rho of adjacent cartilage in knees with acute ACL injuries at $3 \mathrm{~T}$. Osteoarthritis Cartilage. 2009;17(1):12-8. 